\title{
La tutela cautelar en materia de declaración de edificios en estado ruinoso
}

\author{
Fernando González Botija
}

Sumario: 1. INTRODUCCIÓN. 2. PRESUPUESTOS DE LA SUSPENSIÓN CAUTELAR EN MATERIA DE DECLARACIÓN DE RUINA: DOCTRINA JURISPRUDENCIAL. A) La existencia de un perjuicio de difícil o imposible reparación. B) La ponderación del interés general. C) La apreciación del fumus boni iuris. 3. EL PROBLEMA DE LOS EDIFICIOS DEL PATRIMONIO HISTÓRICO-ARTÍSTICO. 4. LA SUSPENSIÓN DE LAS OBRAS DE CONSERVACIÓN.

\section{INTRODUCCIÓN}

El art. 122 de la Ley de la Jurisdicción Contencioso- administrativa dispone que, aunque «la interposición del recurso contencioso-administrativo no impedirá a la Administración ejecutar el acto o disposición objeto del mismo (apartado $\left.1 .{ }^{\circ}\right)$..., procederá la suspensión cuando la ejecución hubiese de ocasionar daños o perjuicios de reparación imposible o difícil» (apartado 2. ${ }^{\circ}$ ).

Por lo tanto, tras proclamarse solemnemente el carácter eminentemente ejecutivo de todo acto administrativo, derivado de la presunción de validez y legitimidad que le ampara al emanar del Poder Público y de la necesidad de que éste actúe con la máxima eficacia ${ }^{1}$, se introduce la salvedad de que es posible suspender dicho acto cuando se puedan producir perjuicios de reparación imposible o dificil.

La interpretación de lo que haya de entenderse por este auténtico concepto jurídico indeterminado presenta dos características importantes:

1. $)$ Ha evolucionado considerablemente a lo largo del tiempo la interpretación que de dicha expresión debía hacerse. Esa evolución se ha visto fundamentalmente impulsada por la Constitución y la consagración del derecho a la tutela judicial efectiva en el art. 24 de la misma. La doctrina tanto jurispruden-

Vid. L. Parejo Alfonso y otros, Manual de Derecho Administrativo. Ed. Ariel. Barcelona, 1992, pág. 798; E. GARCía DE ENTERRIA, «Constitucionalización definitiva de las medidas cautelares contencioso-administrativas y ampliación de su campo de aplicación (medidas positivas), y "jurisdicción plenaria" de los tribunales contencioso-administrativos, no limitada al efecto revisor de los actos previos. Dos sentencias constitucionales", REDA n. 79. 
cial como académica entienden que forma parte del contenido esencial de dicho derecho lo que se ha denominado el «derecho a la tutela cautelan» ${ }^{2}$, es decir, el derecho a que no se frustre el reconocimiento que se pueda hacer al resolverse el asunto de fondo porque la ejecución inmediata del acto administrativo haya creado una situación de hecho irreversible o de dificil resolución que impide que, una vez dictada sentencia anulatoria de dicho acto, se pueda reintegrar a la persona afectada por el mismo en el pleno ejercicio de los derechos e intereses que se han visto afectados al procederse a su ejecución.

2. ${ }^{\circ}$ El derecho a solicitar la suspensión ha experimentado un proceso expansivo que ha llevado a poner en cuestión el principio de que la regla es la ejecución del acto administrativo y la excepción la suspensión. Cada vez son más los ámbitos normativos en que este principio podríamos decir que llega a invertirse ${ }^{3}$, aunque sin llegar al extremo de lo que ocurre en Alemania ${ }^{4}$ a este respecto. Un buen ejemplo de lo que acabamos de decir lo representa en parte la materia concreta que es estudio del presente trabajo: la declaración de ruina de las construcciones.

\section{PPESUPUESTOS DE LA SUSPENSIÓN CAUTELAR EN MATERIA DE DECLARACIÓN DE RUINA: DOCTRINA JURISPRUDENCIAL}

El art. 247 de la actual Ley del Suelo regula la materia de la declaración de ruina en nuestro Derecho. Con base en el texto de dicho artículo, la doctrina ${ }^{5}$ distingue dos modalidades de ruina:

1. ) La llamada ruina ordinaria, que es cuando se declara en ruina un edificio por los motivos enumerados en el apartado $2 .^{\circ}$ del citado artículo: coste de las obras necesarias superior al $50 \%$ del valor del edificio; agotamiento generalizado de los elementos estructurales; y requerirse la realización de obras que no pueden ser autorizadas por encontrarse el edificio en situación de fuera de ordenación.

2 El art. 24,1 de la CE es prácticamente omnipresente en todos los estudios doctrinales que con carácter monográfico se han dedicado a estudiar esta materia. A modo de ejemplo, puede verse: $\mathrm{C}$. CHINCHILLA MARín, La tutela cautelar en la mueva justicia administrativa. Ed. Civitas, 1991, págs. 168 y ss.

3 Ibidem, págs. 145 y ss.

4 Vid. J. BARnes VÁzQUez, «La tutela judicial efectiva en la Constitución alemana», en La Protección Juridica del Ciudadano. Estudios en homenaje al profesor Jesús González Pérez. Tomo II. Ed. Civitas, 1993.

5 Véase J. V. FERRANDO, Edificios ruinosos (supuestos de declaración y procedimiento). Ed. Civitas, S.A., Madrid, 1994, págs. 136-144. 
LA TUTELA CAUTEL,AR EN MATERIA DE DECLARACIÓN..

2.') La denominada ruina inminente, que se produce cuando al existir peligro o urgencia en la demora, el Ayuntamiento o el Alcalde, bajo su responsabilidad y por motivos de seguridad, puede ordenar el desalojo y la demolición inmediata del inmueble [art. 247,4 de la LS y art. 24 del Reglamento de Disciplina Urbanística (RDU)].

Toda declaración de ruina lleva implícita una orden de demolición ${ }^{6}$, la cual debe ejecutarse salvo que se obtenga la suspensión cautelar de la misma. $\mathrm{La}$ posibilidad de lograr esto último supone realizar una valoración conjunta de, en principio, dos elementos: la existencia de un perjuicio de imposible o difícil reparación y la valoración del interés general; a los cuales hay que añadir un tercero que recientemente ha encontrado un fuerte eco y respaldo en nuestra doctrina ${ }^{7}$; me estoy refiriendo a la apreciación del fumus boni iuris o apariencia de buen derecho. A este requisito se le ha definido como «la necesidad de que el recurso se fundamente en un argumento jurídico aparentemente válido que no se identifica tanto con la posibilidad de éxito del recurso como con la valoración sumaria de su no manifiesta falta de fundamentacións? ${ }^{8}$.

\section{A) La existencia de un perjuicio de difícil o imposible reparación}

Podría decirse que no hay mayor perjuicio material de difícil o imposible reparación que el hecho de que se proceda a la demolición inmediata de un edificio. Es cierto que si al dictarse sentencia se llega a la conclusión de que el acto declaratorio de la ruina y la consiguiente demolición eran ilegales, siempre cabe la posibilidad de solicitar una indemnización en la cual se deberá evaluar no sólo el valor del edificio derribado sino también toda una serie de daños sobreañadidos que han tenido su origen en la demolición y que pasamos a estudiar con detalle más adelante. También es verdad que la jurisprudencia ha insinuado que aunque no es posible obligar al Ayuntamiento que ha demolido el inmueble ilegalmente a pagar la reconstrucción de uno nuevo (ya que con ello se produciría un enriquecimiento injusto de los propietarios al ver recibir a cambio de un edificio normalmente muy antiguo uno de reciente construcción), sí es posible que éstos lleguen a un acuerdo con aquél para que colabore en parte en dicha reconstrucción a través de la indemnización que se conceda 9 .

\footnotetext{
6 A. de 3 de noviembre de 1994. Ar. 2801.

7 Véase E. Garcia de EnTERria, La batalla por las medidas cautelares. Ed. Civitas, 1992.

8 Véase C. Chinchilla Marín ... op. cit., pág. 46. Sobre este particular, también puede consultarse R. GÓMEZ-FERRER MORANT, «Apariencia de buen derecho y suspensión en vía contenciosa de actos de carácter tributarion, en La Protección Juridica al Ciudadano. Estudios en homenaje al profesor Jesús González Pérez. Tomo II. Ed. Civitas, 1993, pág. 1.167.
}

9 S. de 2 de febrero de 1993. Ar. 591. 
Sin embargo, pese a todo esto es posible reconocer que la demolición de un edificio es, como mínimo, un daño de dificil ${ }^{10}$ reparación y ello por dos motivos:

1) Aunque es verdad que todo perjuicio de carácter material siempre es reparable más o menos, con una indemnización, no hay que olvidar que una verdadera realización de la tutela judicial efectiva supone, tal y como ha destacado la jurisprudencia " los derechos e intereses que son objeto del litigio, posibilitando, al final de éste, el disfrute de esos mismos derechos o intereses y no una indemnización equivalente en sustitución de ellos impuesta por su desaparición o menoscabo durante el procesol..

2) Por otro lado, la jurisprudencia ha considerado que un perjuicio es de difícil reparación cuando es complicado calcular la indemnización que haya de resarcirlo al obligar al que lo sufre a entablar un nuevo proceso, a menudo largo y costoso, para determinar su cuantía ${ }^{12}$. Éste sería sin duda el caso de un derribo de edificio debido a una declaración de ruina declarada ilegal. Valorar la indemnización que haya de pagarse en este caso es siempre de una extraordinaria complejidad, dado que se acumulan una serie de elementos a considerar, destacados por la jurisprudencia y que pasamos a analizar a continuación.

En primer lugar, hay que poner de relieve que el TS establece de un modo terminante que «toda orden de demolición, por su propia naturaleza, si se ejecuta prematuramente, antes de la culminación del proceso pendiente en el que ha de decidirse acerca de su procedencia y legalidad, puede dar lugar, en el caso de que fuese revocada, a perjuicios de muy dificil o imposible reparacións ${ }^{13}$. Esto lleva a que ha de aplicarse un «criterio restrictivo», el cual «debe presidir cualquier decisión judicial que implique demolición de un inmueble y, con ella, la destrucción de riquezas ${ }^{14}$.

En segundo lugar, debe tenerse en cuenta que el primer gran perjuicio que deriva de la declaración de ruina es que use priva de domicilio a los ocupantes del edificio declarado ruinoso» ${ }^{15}$. Este perjuicio es más patente todavía en los

10 A. de 16 de mayo de 1990. Ar. 4078.

1 Véase C. Chinchilla Marin ... op. cit., pág. 43.

12 A. de 21 de septiembre de 1981. Ar. 3.286. Sobre este particular puede verse, T. FoNT I LLOVET, «Nuevas consideraciones en torno a la suspensión judicial de los actos administrativos». REDA, $\mathrm{n}{ }^{\circ} 34$, 1982, págs. 477 y ss.

13 A. de 27 de noviembre de 1990. Ar. 9299.

14 A. de 9 de diciembre de 1992. Ar. 9750.

15 A. de 17 de julio de 1991. Ar. 6346; A. de 9 de marzo de 1992. Ar. 1597. 
LA TUTELA CAUTELAR EN MATERIA DE DECLARACIÓN..

casos de ruina inminente en los que en un corto espacio de tiempo los moradores del inmueble afectado deben abandonarlo sin poseer derecho alguno al realojo ${ }^{16}$. El quebranto que supone tener que hacer una mudanza, buscar un sitio provisional donde guardar los muebles, poder realojarse e incluso el tener que irse a vivir a otro lugar quizás alejado de aquél en donde se ha habitado a lo largo de mucho tiempo y, puede que también, alejado del lugar habitual de trabajo, supone, aparte de las molestias, una serie de gastos (piénsese, por ejemplo, en los de transporte o gasolina por tener que desplazarse ahora para poder ir a trabajar) que son dificiles de evaluar a largo plazo. Esto se agrava aún más si los ocupantes del inmueble son arrendatarios que deben ir a pleito para resolver sus contratos de alquiler o, en su caso, exigir las posibles indemnizaciones contra el propietario por no cumplir éste con su deber de conservación del inmueble y facilitar así la declaración de ruina.

Sin embargo, la valoración de este perjuicio consistente en la pérdida de la vivienda puede matizarse al tener en cuenta otras circunstancias. Así, en un auto de 1991, el TS ${ }^{17}$ afirma que «los perjuicios que en caso de demolición pueden producirse al recurrente no son tan graves como en la generalidad de los casos al concurrir su calidad de copropietarion. Cuando se hace referencia aquí a la generalidad de los casos, podemos presumir que se está pensando en la típica situación que suele darse en los expedientes de declaración de ruina en que los moradores del inmueble afectado por dicha declaración son inquilinos que disfrutan de contratos de alquiler sometidos a la prórroga forzosa y a la congelación de rentas, en muchos casos pensionistas sin grandes recursos que no pueden afrontar el tener que pagar un alquiler a precios de mercado. En estos casos el propietario siempre es favorable a que se derribe el edificio ${ }^{18}$, siendo dichos arrendatarios los que solicitan la suspensión de la declaración de ruina para evitar verse de un modo inmediato sin lugar a donde ir. Pero puede ocurrir que el edificio afectado por el estado ruinoso esté habitado por sus propietarios en su totalidad o en parte. En este caso, el problema de la pérdida de la vivienda no es tan acuciante porque el propietario conserva su derecho intacto sobre el solar y puede vender éste rápidamente para poder así adquirir una nueva casa e, incluso llegar a ganar dinero con la operación si la situación del mercado y el aprovechamiento urbanístico le resultan favorables ${ }^{19}$. Sin embargo, esto último no puede verse como una verdad absoluta. Es igualmente posible que los propietarios del inmueble, pese a su condición de tales, tengan

16 Es decir, no hay un derecho a obtener por parte del Ayuntamiento una vivienda a cambio de la que se ha declarado en tal estado.

17 A. de 3 de enero de 1991. Ar. 490.

18 Situación que puede empezar a cambiar con la nueva LAU.

19 Lo cual dependerá de las circunstancias de cada caso concreto. 
razones más que suficientes para oponerse a la declaración de ruina. Éste será el caso cuando atendiendo a lo que presumiblemente se pueda obtener con la venta del solar, esto no les dé para adquirir una nueva vivienda en la zona donde está situado el edificio ruinoso, lo cual puede fácilmente ocurrir si lo obtenido con la venta del solar es poco por no permitir el Plan que se puedan construir muchos $\mathrm{m}^{2}$ y se deba repartir entre muchos propietarios y copropietarios. Esto además se puede complicar si la evolución del precio de la vivienda en la zona es excesivamente al alza.

El segundo gran perjuicio que puede producirse es si existen locales de negocios o industrias. En estos casos el daño deriva upor la propia naturaleza de la actividad industrial que alli se desarrolla» al existir «instalaciones de rendimiento económico" ${ }^{20}$. A la situación de los locales de negocio o industrias cabe equiparar la vivienda cuando se destina al ejercicio de una actividad profesional (piénsese en el caso de que haya consultas de médicos, dentistas, abogados, etc.) ${ }^{21}$. En estos casos el problema reside en que la declaración de ruina va a paralizar una actividad comercial, industrial o profesional lo cual va a suponer «unas pérdidas negociales poco fáciles de concretar y por consiguiente de resarcir» ${ }^{22}$. A las molestias que hemos visto se producen en el caso de la vivienda hay que añadir el hecho de que durante un cierto tiempo, que puede ser más o menos largo, no se va a poder trabajar ni obtener ingresos. A esto habrá que sumar, sobre todo en el caso de los locales de negocios, que el traslado a una nueva zona supone afrontar la pérdida de la clientela anterior y la necesidad de ganar allí una cuota de mercado que ya se tenía asegurada en el lugar donde estaba el inmueble declarado en ruina. Esto puede ser aún más grave y más difícil de resarcir con una indemnización cuando se tiene que abandonar una zona o un lugar muy frecuentado y de gran actividad comercial que por su situación y teniendo en cuenta también la naturaleza del negocio puede ser inmejorable. En este sentido, la pérdida comercial puede ser indefinida de no poder retornarse jamás a dicho sitio. Lo cierto es que el comentario realizado arriba sobre la influencia que puede tener sobre la valoración de la gravedad del perjuicio el hecho de que se sea propietario o arrendatario, se puede aplicar igualmente en este supuesto.

Finalmente, hay que destacar que en algún auto se llega a introducir como elemento a tener en cuenta para valorar el daño la solvencia económica del Ayuntamiento que ha daclarado la ruina. Así se establece en un auto de $1992^{23}$ al afirmarse

\footnotetext{
20 A: de 9 de marzo de 1993. Ar. 1597; A. de 9 de diciembre de 1992. Ar. 9750.

21 A. de 17 de julio de 1991. Ar. 6346; A. de 15 de marzo de 1993. Ar. 1716.

22 A. de 30 de diciembre de 1992. Ar. 9782.

23 A. de 10 de junio de 1992. Ar. 5068.
} 
que «no debe caber duda racional alguna, ante la solvencia económica del Ayuntamiento de Motril, que ha declarado la ruina de que la indemnización correspondiente por los daños y perjuicios sufridos estaría asegurada en la medida justa».. Esta afirmación hace recordar inevitablemente la jurisprudencia anterior a la Ley de la Jurisdicción de 1956, en virtud de la cual se mantenía una actitud reacia a acordar la suspensión al entenderse que la Administración siempre era solvente y siempre podría indemnizar con dinero los perjuicios que cause. Esta teoría fue definitivamente rechazada por la Ley de 1956 en cuya Exposición de Motivos se afirma que «respecto a la dificultad de la reparación no cabe excluirla sin más por la circunstancia de que el daño o perjuicio que podría derivarse de la ejecución sea valorable económicamente». Esta afirmación del anterior auto citado hay que interpretarla más dentro de su contexto (se trataba de una declaración de ruina inminente que, como veremos más abajo, constituye una importante excepción a la regla) que como una vuelta a esa antigua jurisprudencia.

Como conclusión podemos decir que, en la evaluación de la magnitud del perjuicio que se deriva de la ejecución del acto declaratorio de la ruina, el juez deberá tomar en consideración el conjunto de elementos arriba vistos en la medida en que se presenten en cada caso concreto.

\section{B) La ponderación del interés general}

En el terreno de la tutela cautelar la valoración del interés público en juego es determinante a la hora de conceder o no la suspensión del acto. En el juicio cautelar se trata de saber siempre cuál de los dos valores colocados en los platillos de la balanza de la justicia pesa más: el perjuicio que sufre el particular porque se ejecute el acto o el interés público que se realiza con su ejecución. En el caso concreto de la declaración de un edificio en ruina, una vez visto en qué consiste el perjuicio del particular, el interés general sobre el que se asienta el acto administrativo declaratorio reside en garantizar la seguridad pública de personas y bienes evitando la existencia de edificios que de un modo potencial (caso de la ruina ordinaria) o actual (caso de la ruina inminente) pueden constituir una amenaza para la misma al poderse producir su derrumbamiento ${ }^{24}$. La diferencia entre ambos casos es esencial en este campo, pues, aun existiendo en los dos un interés público, van a ser distintas las consecuencias que se deriven de la invocación de uno u otro a la hora de decidir si se concede o no la suspensión del acto de declaración de ruina y la consiguiente orden de demolición, o, lo que es lo mismo, si el perjuicio de difícil o imposible reparación que su- 
pone siempre la demolición de un inmueble prevalece o no sobre el interés público y si el edificio, hasta que no se dicte sentencia, se derriba o no.

La doctrina del TS al respecto es la siguiente:

«Esta pieza separada de suspensión deriva de un recurso en el que se impugna una declaración de ruina y, sobre esta base, la reflexión necesaria para adoptar la decisión procedente en relación con lo dispuesto en el artículo 122,2 de la Ley Jurisdiccional..., exige ante todo una clara distinción:

A) En los casos de ruina inminente, la posibilidad de un derrumbamiento inmediato de la edificación implica un grave peligro para las personas que, en cuanto interés profundamente relevante, impide el pronunciamiento suspensivo.

B) Pero en los supuestos de ruina ordinaria, dado que su fundamento radica en que ya no resulta socialmente justificado el gasto de la reparación..., la solución ha de ser otra.

La declaración de ruina implica ante todo una orden de demolición..., lo que obliga a recordar que una reiteradísima jurisprudencia viene destacando que la demolición da lugar a una destrucción de riqueza que puede resultar injustificada en caso de estimación del recurso contencioso-administrativo y que, por tanto, salvo exigencias inmediatas del interés público ha de evitarse en tanto no exista sentencia firme» ${ }^{25}$.

Esta doctrina jurisprudencial no puede ser mas coherente y proporcionada. Coherente porque se corresponde de un modo preciso con el concepto que los Tribunales han creado de los dos tipos de ruina. Por un lado, la ruina inminente «implica una situación de un edificio o construcción que ofrezca tal deterioro que haga urgente su demolición y existe peligro para las personas o los bienes con la demora que supondría la tramitación del expediente de ruina normal» ${ }^{26}$. Esta situación de peligro se interpreta no en el sentido de restringirla al caso en que se tenga seguridad de que se vaya a producir el derrumbamiento del edificio de un modo inmediato, sino en un sentido más amplio al interpretarla desde el punto de vista de la "previsibilidad»" ${ }^{27}$ de dicho derrumbamiento, es decir, basta con que se pueda prever la "posibilidad del mismo»" ${ }^{28}$ aunque no se pueda determinar con exactitud más o menos próxima que se va a producir. Por

\footnotetext{
25 A. de 13 de enero de 1994. Ar. 2404. Véase también A. de 20 de abril de 1995. Ar. 3163.

S. de 2 de febrero de 1993. Ar. 580

S. de 25 de junio de 1991. Ar. 5253.

28

A. de 3 de noviembre de 1994. Ar. 2801.
} 
LA TUTELA CAUTELAR EN MATERIA DE DECLARACIÓN...

otro lado, el concepto de ruina ordinaria parte igualmente de un problema de seguridad, pero más difuso o indefinido al tener su base en el posible grado de deterioro que podría sufrir un inmueble por el hecho de que al encontrarse en los supuestos del art. 247,2 de la LS se entiende que el deber de conservación del edificio no se le puede seguir imponiendo al propietario una vez que se ha pasado cierto límite ${ }^{29}$.

La tesis jurisprudencial es proporcionada porque según el peso del interés público en juego se le hace prevalecer o no sobre el interés privado consistente en evitar los perjuicios derivados de la demolición del inmueble. En el supuesto de la ruina inminente, dado el real peligro de caída del edificio que existe, el bien público que hay que proteger no puede ser más importante, pues «lo que está en juego es la vida de las personas" ${ }^{30}$. Así, se afirma en un auto de $1991^{31}$ que «la declaración de ruina inminente lleva en sí misma tal carga de riesgo y peligrosidad para el conjunto de los ciudadanos y para los habitantes de la finca afectada por ella, que lo elementalmente aconsejable es..., la no suspensión del acto administratrivo que contenga aquella declaración, ante la evidencia de que el interés público y general debe prevalecer sobre el particular del titular de la fincay. Esto es así aunque en el momento de sustanciarse la medida cautelar el Ayuntamiento no haya procedido aún al derribo del edificio o no haya adoptado medidas de seguridad al respecto ${ }^{32}$.

Por otro lado, esto viene a situarse en la línea de la jurisprudencia que destaca que, a la hora de declarar una ruina inminente, en caso de duda, ha de prevalecer la seguridad de los vecinos, debiéndose valorar el hecho de que en el edificio existan locales de negocio que suelen encontrarse habitualmente muy concurridos ${ }^{33}$.

Por consiguiente, en los supuestos en que no quede demostrada esta peligrosidad procede decretar la suspensión ${ }^{34}$. Puede ocurrir que dicha situación

29 Límite marcado por la existencia de uno de los supuestos de ruina establecidos en el art. 247 de la LS. Véase S. de 10 de junio de 1991. Ar. 4871.

30 A. de 9 de octubre de 1990. Ar. 7851.

31 A. de 3 de enero de 1991. Ar. 490.

32 Otra cosa será la posible exigencia de responsabilidades que se le puedan reclamar por actuar de un modo negligente. No olvidemos que el art. 247,4 de la LS recuerda que el Ayuntamiento en los casos de peligro o urgencia en la demora actúa «bajo su responsabilidad». Sobre las dudas interpretativas que plantea este precepto, puede verse J. GARCIA-BELLDO, «Nuevos enfoques sobre el deber de conservación y la ruina urbanisticas. $R D U$, n. $^{\circ} 89,1994$, pág. 71.

33 S. de 23 de abril de 1992. Ar. 3841.

34 A. de 9 de diciembre de 1992. Ar. 9750. 
no esté muy clara, incluso que se alegue la existencia de vicios ocultos ${ }^{35}$. En estos casos de duda seguirá siendo procedente la suspensión hasta que no se confirme y se decrete oficialmente el estado de ruina inminente; sin embargo, dado el carácter evolutivo del estado ruinoso del edificio ${ }^{36}$, el TS en su jurisprudencia recuerda el deber que tienen los técnicos municipales, con base en los arts. 20, 26 y 27 del RDU, de girar las visitas de inspección a la finca que sean necesarias para controlar dicha evolución, así como la potestad que poseen de ordenar a la propiedad que adopte las medidas de seguridad (por ejemplo: apeos y apuntalamientos) «urgentes y necesarias para mantener el edificio en condiciones de seguridad...». Es por ello que la suspensión en estos casos se subordina a la prestación de "caución cuyo importe se fijará en ejecución del auto y que corresponderá a la cuantificación económica de las indicadas medidas» ${ }^{37}$. Esta última medida encuentra su justificación plena en el art. 124,1 de la Ley Jurisdiccional, el cual dispone que «cuando el Tribunal acuerde la suspensión exigirá, si pudiera resultar algún daño o perjuicio a los intereses públicos o de tercero, caución suficiente para responder de los mismos».

\section{C) La apreciación del fumus boni iuris}

No vamos a entrar aquí en la polémica que existe en nuestra doctrina sobre el peso que se le ha de dar a este requisito a la hora de acordar la tutela cautelar ${ }^{38}$. Lo que sí resulta evidente a la luz de los autos de suspensión de actos declaratorios de ruina es que el fumus boni iuris, entendido como un examen superficial encaminado a saber a favor de qué parte juega la apariencia de buen derecho, tiene un peso secundario frente al que poseen los otros dos elementos. Normalmente, en la valoración de una declaración de ruina los informes periciales tienen un valor fundamental al consistir aquélla en el esclarecimiento técnico de una situación de hecho: la existencia o no del estado ruinoso y su intensidad (ordinario o inminente). Sin embargo, la jurisprudencia nos recuerda que «sabido es que en una pieza de suspensión no puede examinarse la cuestión referente a la legalidad del acto administrativo impugnado en los autos principales», por lo que «no puede entrarse a valorar, a los efectos de

\footnotetext{
35 A. de 27 de noviembre de 1990. Ar. 9299.

36 S. de 5 de junio de 1991. Ar. 4868.

37 A. de 11 de noviembre de 1993. Ar. 8336. Deberá tenerse en cuenta la solvencia de la propiedad.

38 Sobre este aspecto se puede contrastar lo afirmado por E. GARCí DE ENTERRiA en las obras antes citadas con lo afirmado por E. CocA VIrA, «A vueltas con la suspensión de la ejecución de actos administrativos recurridos. Ültimas aportaciones doctrinales y jurisprudenciales». RAP, $\mathrm{n}^{\circ} 127 \mathrm{y}$ C. CHIN CHILLA MARIN ... op. cit., págs. 171 y ss.
} 
LA TUTELA CAUTELAR EN MATERIA DE DECLARACIÓN...

decidir sobre la referida legalidad, los informes periciales aportados a los autos» ${ }^{39}$. No pudiéndose entrar en la valoración de los informes periciales en el juicio cautelar por prejuzgarse el fondo del asunto poco juego se le deja al requisito del fumus, aunque no puede decirse que se produzca un olvido absoluto del mismo, ya que cuando se invoque la ruina inminente por el Ayuntamiento, pese a que el juez no pueda examinar los informes presentados por los particulares en que alegan la falta de la misma, por prejuzgar el fondo del asunto, dada la gravedad de dicho tipo de declaración (hemos visto como no se concede la suspensión), el juez sí podrá estudiar por encima el informe de los técnicos municipales que sirve de base a dicha declaración. Será aquí fundamentalmente donde el fumus desarrolla todo su sentido en este campo, aunque en la práctica no servirá para impedir la ejecución del acto declaratorio de la ruina inminente más que en el caso de que, de un modo manifiesto, se demuestre con una superficial lectura del mismo que ha existido un evidente error de hecho (por ejemplo, que se declarase un número de edificio contiguo al afectado), falta absoluta de motivación o desvío de poder.

En este sentido, también estaría justificada la suspensión en este caso si el acto de declaración es manifiestamente nulo de pleno Derecho, en virtud de lo dispuesto en el art. 62,1 de la Ley de Procedimiento actual. Con base en el art. 111 de dicha Ley ya se debería haber procedido a dicha suspensión en vía administrativa, pero no hay que olvidar que la jurisprudencia ha venido aceptando esta causa de suspensión de acuerdo con el antiguo art. 116 de la LPA en relación con el art. 47 de esta ley ${ }^{40}$.

En el supuesto de la ruina ordinaria, dado el peso tan considerable que tienen los perjuicios derivados de la demolición del inmueble en relación con el poco relevante interés público que se invoca, no parece posible que un fumus favorable a este último deba anular la regla de la suspensión automática. La relevancia de los intereses particulares en presencia merece que el edificio se mantenga en todo caso en pie hasta que se haga un examen detallado de la legalidad de la declaración.

\section{EL PROBLEMA DE LOS EDIFICIOS DEL PATRIMONIO HISTÓRICO-ARTÍSTICO}

En el caso de que se declare en ruina un edificio de estas caracteristicas, la Ley del Patrimonio Histórico Español de 1985 dispone que no se podrá proceder a la

39 A. de 9 de octubre de 1990. Ar. 7851.

40 Vid. R. SASTRE LEGDO, «La suspensión de los efectos del acto administrativo objeto de recurso». $R A P$, n. $^{\circ} 30$, pág. 255. 
demolición de un inmueble sin previa firmeza de la declaración de ruina y auttorización de la Administración competente, que no la concederá sin informe favorable de al menos dos de las instituciones consultivas a las que se refiere el art. 3 (art. 24,2). En los casos de ruina inminente tampoco es posible proceder a la demolición sin la autorización correspondiente (art. 24,3 y art. 16,1). En este sentido, la jurisprudencia del $\mathrm{TS}^{41}$ ha reconocido la legalidad de toda actuación de la Administración competente dirigida a suspender el acto municipal que ordena que se proceda a la demolición de este tipo de edificios, sea la declaración de ruina ordinaria o inminente ${ }^{42}$.

En el supuesto que dicha autorización no se conceda cabría preguntarse si en la vía jurisdiccional se podría conseguir que cautelarmente se concediese el permiso de demolición suspendido en vía administrativa. La respuesta debería ser negativa, dado que es un principio esencial de las medidas cautelares el que no se puede conceder a través de ellas precisamente lo que la Administración no nos ha concedido al dictar un acto negativo (en este caso, no permitir la demolición) ${ }^{43}$.

En el caso de que dicha autorización se conceda y se impugne ante los Tribunales es lógico pensar que son de aplicación las reglas generales vistas al examinar la ponderación del interés público.

\section{LA SUSPENSIÓN DE LAS OBRAS DE CONSERVACIÓN}

En muchas ocasiones la Administración ordena a los propietarios de inmuebles que ejecuten obras de conservación de los mismos, fundamentalmente por motivos de seguridad, con base en los arts. 245 de la LS y 10 del RDU. Esta orden encuentra a veces la oposición de los particulares que consideran que su deber de conservación del edificio se ha extinguido por estar éste en ruina. Por lo tanto, aparte de introducir un recurso para obtener en vía judicial la declaración de la misma, los propietarios intentan conseguir la suspensión de la orden de obras para evitar que se ejecuten éstas, dado que dicha ejecución podía suponer la desaparición del estado ruinoso, única base sobre la cual se puede declarar o no en ruinas un edificio. Es decir, el hecho de que un inmueble se encontrase en tal situación pero ésta desapareciese debido a la ejecución de las obras ordenadas por el Ayuntamiento, no posibilita la declaración de ruina si ésta ya no existe en el momento de dictarse sentencia, al tener que basarse sobre la

41 S. de 20 de noviembre de 1991. Ar. 9154.

42

Ibidem.

43

Vid. C. ChInchilla Marín ... op. cit., págs. 123 y ss. 
LA TUTEL A CAUTELAR EN MATERIA DE DECLARACIÓN...

situación de hecho que presente el inmueble en el momento actual y no pasado $e$ independientemente de la causa que haya motivado la desaparición del estado ruinoso (en este caso, las obras ordenadas por el Ayuntamiento).

Como esto supone una verdadera indefensión y una frustración del derecho de los particulares a que se les permita demostrar ante los Tribunales el estado ruinoso del edificio, por consiguiente, una frustración de su derecho a la tutela judicial efectiva, el TS viene reconociendo «que procede la suspensión de la ejecución de dicha resolución en razón, fundamentalmente, a que las obras en cuestión harán desaparecer una situación de hecho que se trata de acreditar a los efectos de obtener la declaración de ruina de la edificación, privando de esta forma al solicitante de aquélla de la posibilidad de aportar elementos probatorios en apoyo de su derecho». Pero se matiza «que dicha suspensión se decreta sin perjuicio de las obras precisas por razones urgentes y perentorias de seguridad de las personas y cosas» ${ }^{44}$.

El problema reside en saber qué hay que entender exactamente por dichas "obras indispensables para la seguridad». A la vista de la jurisprudencia ${ }^{45}$, parece claro que se trata de obras de reparación con base en el art. 245 de la LS (antiguo art. 181) y no de estrictas medidas de seguridad del art. 26 del RDU (apeos y apuntalamientos) que también pueden decretarse aparte ${ }^{46}$. Dado que sólo pueden realizarse las que sean «indispensables» 0 «imprescindibles») para la seguridad ${ }^{47}$, es lógico incluir entre las mismas exclusivamente aquellas tendentes a evitar derrumbamientos de partes del edificio o de su conjunto. En ningún caso podrán admitirse obras que por su costo sean desproporcionadas y prejuzguen la declaración de ruina ${ }^{48}$. Siempre es posible, en aplicación del art. 124,1 de la Ley Jurisdiccional, fijar una caución por el valor de las mismas ${ }^{49}$.

\footnotetext{
44 A. de 19 de diciembre de 1991. Ar. 312.

45 A. de 30 de diciembre de 1992. Ar. 10417.

46

S. de 13 de junio de 1990. Ar. 4822.

47 A. de 25 de septiembre de 1990. Ar. 7383. A. de 30 de diciembre de 1992. Ar. 10417.

48 A. de 30 de diciembre de 1992. Ar. 10417.

49

Véase nota 16.
} 
